\title{
A docência entre o ideal republicano e as violências do cotidiano
}

\author{
Libania Xavier $^{1}$ \\ ORCID: 0000-0003-4422-2118
}

\section{Resumo}

0 artigo é fruto de pesquisa em curso e tem como base um conjunto de depoimentos de professoras e diretoras atuantes em escolas públicas do Rio de Janeiro, localizadas em territórios conflagrados por conflitos armados. Este estudo está dividido em quatro tópicos. 0 primeiro apresenta o universo pesquisado e o segundo, observa como jovens professoras percebem o seu papel profissional e se comportam diante das explosões de violência em que, muitas vezes, se veem envolvidas. 0 terceiro tópico analisa os depoimentos de professoras que exerceram cargos de direção, perscrutando os modos de lidar com a violência em seu cotidiano, e o quarto tópico aborda as percepções partilhadas pelas professoras sobre a relevância de seu trabalho, indicando que o ideal da educação pública-republicana ainda se impõe no interior de suas escolas. 0 enfoque escolhido foi as táticas que elas articulam em situações de violência, em vista de suas experiências pregressas e das expectativas que nutrem em relação ao seu futuro. Para tanto, elegeramse duas questões que orientam as análises apresentadas, a saber: que razões motivaram as professoras a permanecerem nas escolas localizadas em territórios conflagrados, apesar dos riscos? Que argumentos ancoram tal decisão? Por meio delas, é possível perceber os processos pelos quais essas professoras produzem uma cultura profissional própria, na interseção entre as narrativas que elas constroem sobre sua trajetória profissional e o projeto de construção democrática que, historicamente, tem dado sentido à escola pública.

\section{Palavras-chave}

História da educação - Profissão docente - Construção democrática.

1- Universidade Federal do Rio de Janeiro, Rio de Janeiro, RJ, Brasil. Contato: libanianacif@gmail.com 


\section{Teaching between the republican ideal and everyday violence}

\section{Abstract}

The article is the result of ongoing research and is based on a set of testimonies from teachers and principals working in public schools in Rio de Janeiro, located in territories conflagrated by armed conflicts. This study is divided into four topics. The first presents the universe researched and the second observes how young teachers perceive their professional role and behave in the face of the explosions of violence in which they often find themselves involved. The third topic analyzes the testimonies of teachers who held management positions, examining the ways of dealing with violence in their daily lives, and the fourth topic addresses the perceptions shared by teachers about the relevance of their work, indicating that the ideal of Republic public education still imposes itself inside the schools. The chosen focus was the tactics they articulate in situations of violence, in view of their past experiences and the expectations they have regarding their future. Therefore, two questions were chosen to guide the analyzes presented, namely: what reasons motivated the teachers to remain in schools located in conflicted territories, despite the risks? What arguments support such a decision? Through them, it is possible to perceive the processes by which these teachers produce their own professional culture, in the intersection between the narratives they build about their professional trajectory and the democratic construction project that, historically, has given meaning to public school.

\section{Keywords}

History of education - Teaching profession - Democratic construction.

\section{Apresentação}

0 artigo apresenta resultados parciais de uma pesquisa em curso que visa compreender como, em nossa história recente, os docentes lidam com as situações de violência que marcam a vida dos moradores de territórios conflagrados do Rio de Janeiro ${ }^{2}$. Rogério Haesbaert (2004) assinala a dupla conotação, material e simbólica, do termo território, que estaria ligada às relações de poder e dominação, articulando tanto a dominação políticoeconômica quanto a apropriação mais subjetiva e/ou cultural. Abordando a questão empiricamente, Marcelo Burgos (2005) ajuda a compreender a segregação espacial do Rio de Janeiro ao assinalar as diferenças entre cidade e território. Para o autor, o conceito de território engloba diferentes tipos de habitação popular (incluindo as favelas) e se diferencia da cidade em razão da ausência de condições mínimas para o exercício dos

2- Trata-se de pesquisa que contou com bolsa Pq-CNPq (2018-2021) e Pibic-CNPq e UFRJ (2018-2020), intitulada Associativismo docente e construção democrática: o exercício da docência em áreas de risco na cidade do Rio de Janeiro. 
mais elementares direitos civis, a começar pela integridade física. Evocando o conceito de cidade escassa ${ }^{3}$, o autor chama atenção para a baixa capacidade de o Estado impor lei e ordem, bem como de fazer cumprir os direitos dos habitantes desses territórios, o que os torna vulneráveis à imposição das vontades dos poderosos (BURG0S, 2005).

Nesses territórios, a escola e os professores enfrentam graves dificuldades para criar uma cultura cívica geradora de solidariedade e de participação política. Os professores que atuam nessas escolas se encontram expostos à violência, que se acentua com as operações policiais e os tiroteios que ocorrem no entorno e à sua revelia. Assim, professores e gestores dessas escolas precisam cuidar da segurança de seus alunos e de sua própria integridade física, contando com apoio insuficiente das autoridades gestoras e governamentais. Apesar de tudo, muitos professores seguem realizando seu trabalho, sem pensar em abandonar a escola, criando alternativas para contornar tais situações e fazendo valer o compromisso profissional com os princípios que ancoram o seu trabalho. Diante dessa constatação, algumas questões se tornaram relevantes para o desenvolvimento inicial desta pesquisa, a saber: que argumentos justificam a permanência nessas escolas, apesar dos riscos de morte a que os docentes estão sujeitos? Em que medida esses argumentos expressam modos de politização das práticas e podem ser generalizados, compondo um comportamento padrão e uma cultura profissional própria?

0 texto está estruturado em quatro tópicos. 0 primeiro apresenta o universo estudado, identificando as professoras que colaboraram com a pesquisa e as características dos contextos territorial e institucional em que atuavam. 0 segundo, observa como jovens professoras percebem seu papel profissional e como se comportam diante das situações de violência que atrapalham seu trabalho. 0 terceiro aborda os depoimentos de professoras que exerceram cargos de direção, perscrutando os modos de lidar com a violência em seu cotidiano. 0 quarto tópico procura articular ideias sobre as condições de trabalho permeadas pela violência do entorno da escola e as percepções que as professoras partilham sobre a relevância de seu trabalho para os alunos que habitam esses territórios, indicando que o ideal da educação pública-republicana ainda se impõe no interior de suas escolas. Nesse empenho, centra-se o foco sobre os comportamentos que elas articulam nessas situações, em vista de suas experiências pregressas e das expectativas que nutrem em relação ao seu futuro. Nas considerações finais, sugerem-se algumas hipóteses que justificariam a permanência das professoras nas escolas, a despeito da violência que as cercam, considerando que estas poderão ensejar desdobramentos em debates futuros.

Espera-se perceber os processos por meio dos quais os professores produzem uma cultura profissional própria, na interseção entre o seu projeto profissional e o projeto de construção democrática que, historicamente, tem dado sentido à escola pública. Como afirma Ribeiro (2000), para ser duradoura, a democracia necessita do regime republicano e este, acrescenta-se, tem na escola pública um de seus pilares fundamentais. A literatura sobre o tema tem demonstrado que o projeto de construção da sociedade democrática e do cidadão de mentalidade racional e conduta civilizada, que lhe é próprio, é o que,

3- Termo cunhado por Maria Alice Rezende de Carvalho (2000 apud BURGOS, 2005) que articula o urbano e o político, assinalando a ausência de cultura cívica como chave para se compreender o cotidiano violento das grandes cidades brasileiras. 
historicamente, dá sentido à existência da escola (pública, sobretudo) e ao trabalho do professor (DUBET, 2002).

\section{Contextos adversos ao ideal republicano}

Nas últimas quatro décadas, ocorreram mudanças significativas em nosso país, impulsionadas, sobretudo, pelos esforços de construção democrática que se seguiram com o fim do regime militar (1964-1985), tendo como seu marco institucional a Constituição de 1988. Tais mudanças incluíram a expansão da escola de massas e a consequente ampliação do número de professores atuantes nas redes públicas de ensino. Deve-se registrar, também, a complexificação das relações dos professores com os seus alunos e com as comunidades que cercam a escola ${ }^{4}$.

Outras mudanças, mais estruturais, interferiram na paisagem das grandes cidades, demarcando o crescimento da violência e da insegurança, visível no gradeamento de prédios e praças e no esvaziamento dos espaços de convivência social. No processo de retraimento dos espaços de sociabilidade, Richard Sennett (1999) enfatiza o declínio do homem público, chamando atenção para o individualismo, que se expande em meio à emergência de uma estética das aparências. Essa se desdobra na classificação dos cidadãos em duas categorias: os de primeira classe, aqueles que exibem os signos de consumo e podem pagar por serviços como educação, saúde, cultura e lazer; e os demais, que não têm condições de exibir ou obter signos e serviços e são desvalorizados e desconsiderados socialmente. Nesse contexto, o desejo de possuir bens que garantam reconhecimento social repercute em situações que vão desde pequenos furtos até a participação no crime organizado. A repressão a essas ações por meio de operações policiais tem gerado danos permanentes e, não raro, drásticos à população desses territórios. Portanto, se o regime republicano, que conforma o aparato institucional-legal das democracias, ainda está avançando em nosso país, a concretização dos ideais democráticos, fundados na distribuição dos bens e dos direitos básicos a todos, está longe de se efetivar.

Sabe-se que, por ser uma instituição pública - que forma, informa e socializa os alunos, criando o público e fixando os seus sentidos - a escola compõe um universo muito mais amplo que transcende o ensino de conteúdos formais. Por outro lado, trabalhar sobre e com aqueles que vivem à margem dos direitos consignados na lei, com acesso restrito à saúde e à cultura legítima, bem como à justiça (no sentido ético e jurídico do termo), é tarefa de monta que recai sobre os profissionais que atuam sobre o outro, entre eles os professores (DUBET, 2002).

A margem de insegurança que recai sobre a integridade física e psíquica dos moradores e de todos os que frequentam as escolas situadas nesses territórios tem efeitos imprevistos. Algumas vezes o medo e o desânimo, outras a revolta, o preconceito e a violência replicada aparecem como reverberações dessa situação. A boa notícia é que,

4- De acordo com dados do Departamento Intersindical de Estatísticas e Estudos Socioeconômicos (DIEESE), o número de professores da educação básica aumentou de 2,5 milhões para 3,3 milhões, entre 2002 e 2013, com um crescimento de 32,9 por cento. Nos últimos anos, a elevação foi intensificada, pois até setembro de 2006, a variação era de 3,0 por cento e de 2006 a 2013, 0 aumento foi de 28,8 por cento. Disponível em: https://www.dieese.org.br/notatecnica/2014/notaTec141DocentesPnadvf.pdf. Acesso em: 29 jan. 2020. 
entre os professores que colaboraram com a equipe, encontraram-se atitudes de resistência à reprodução das desigualdades educacionais e à validação das diferentes formas de exclusão social pela e na escola, a despeito das adversidades. Isso explica a opção por dialogar com professores que comungam uma percepção positiva e propositiva do seu trabalho, dando destaque às memórias e às narrativas que eles constroem sobre suas trajetórias profissionais, por acreditar que uma metodologia mais seletiva e qualitativa poderia atender mais diretamente aos objetivos do trabalho.

De toda forma, o grupo de professores, as instituições e as regiões recortadas atendem a um conjunto de características comuns. Primeiro, são áreas que surgiram da ocupação espontânea de migrantes de vários estados do Brasil, em razão da carência de emprego, de recursos financeiros e de conhecimentos que lhes propiciassem maior acesso a direitos, bens e serviços. Também são formadas por habitações pobres, onde a população sofre ou já sofreu com falta de saneamento básico, segurança policial, áreas de lazer e atendimento à saúde. Esses locais experienciam conflitos constantes entre traficantes e policiais, que não respeitam a área em que alunos e professores transitam ou permanecem. Por fim, são áreas em que a ausência de políticas de segurança eficazes levou os professores a criarem suas próprias táticas de proteção.

A equipe considerou que estabelecer um diálogo com dois grupos de professores de diferentes faixas etárias e que atuam em escolas que atendem a diferentes níveis de ensino poderia contribuir para determinar contrapontos e diferenças, bem como para identificar padrões comuns no tratamento da questão, a despeito das particularidades locais, institucionais e subjetivas que configuram múltiplas formas de exercício da docência 5 . Foram definidos os seguintes grupos de professores que aceitaram participar pesquisa ${ }^{6}$ :

- Jovens professoras atuantes em uma Escola de Educação Infantil da rede municipal, localizada na Sexta Coordenadoria Regional de Educação (CRE), que conta com 113 escolas municipais e abrange os bairros de Acari, Anchieta, Barros Filho, Cascadura, Coelho Neto, Colégio, Costa Barros, Deodoro, Guadalupe, Irajá, Parque Columbia, Parque Anchieta, Pavuna, Ricardo de Albuquerque;

- Professores e ex-diretores atuantes em escolas da rede pública do Rio de Janeiro, localizadas na Primeira e na Sétima CRE e na Primeira e Quarta Coordenadorias Metropolitanas do Estado do Rio de Janeiro (SEEDUC/RJ) ${ }^{8}$. Para este artigo, realizou-se recorte de um grupo que atua em uma escola de Ensino Fundamental e Educação de Jovens e Adultos da Quarta CRE, que reúne166 escolas municipais e abrange os bairros de Bonsucesso, Manguinhos, Maré, Olaria, Pavuna e Penha9 .

5- Refere-se à equipe que compõe o grupo de pesquisa Processos Educacionais e História da Profissão Docente, no âmbito do Programa de Pós-graduação em Educação da Universidade Federal do Rio de Janeiro, sob coordenação da autora.

6- A referência às áreas de abrangência das respectivas Coordenadorias Regionais de Educação (CREs) foi extraída da Cartela da Secretaria Municipal de Educação do Rio de Janeiro (SME/RJ), disponível em: http://webapp.sme.rio.rj.gov.br/jcartela/publico/pesquisa.do?cmd=listCres. Acesso em: 15 jan. 2020.

7- Processo no 07/006.510/2017 - Aprovada - Secretaria Municipal de Educação (SME/RJ).

8- Processo no E03/007/5111/2017 - Aprovado - Secretaria Estadual de Educação (SEEDUC/RJ).

9- As pesquisas seguem os protocolos de referência do Comitê de Ética em Pesquisa - CEP (CAAE: 10903719.3.0000.5582) e das Secretarias de Educação envolvidas, que recomendaram o sigilo em relação à identificação dos professores que colaboraram com a equipe, bem como das respectivas escolas. Por esse motivo, apenas a região das escolas em que as professoras se encontravam lotadas são reveladas. 
A opção por trabalhar com as memórias e as histórias orais de professores permite reparar uma tendência a seu silenciamento. Como assevera Campagnucci (2014), ainda que a liberdade de expressão seja um direito constitucional, na prática vigoram mecanismos administrativos e burocráticos que interditam as vozes dos professores, visando prevenir potenciais repercussões negativas advindas de suas declarações públicas. Assim, o recurso ao diálogo com professores e à metodologia da história oral representa uma opção pelo que Loriga (2009) chamou de memória positiva, aquela que repousa no reconhecimento da contribuição pública dos professores, assim como atribui importância às histórias que o estudo de suas trajetórias profissionais revela.

\section{A docência como direito}

As quatro professoras da Unidade de Educação Infantil da Sexta CRE eram cursistas ou egressas dos cursos de pedagogia de universidades públicas do Rio de Janeiro, o que facilitou o contato com a equipe. Elas tinham entre 24 e 29 anos, além de estarem em início de carreira - entre três e sete anos de exercício profissional. Todas tinham sua rotina extremamente afetada por tiroteios que, segundo elas assinalaram à época (20142015), ocorriam quase diariamente na hora da entrada. Tal situação restringia os usos dos espaços externos da escola e amedrontava alunos e professores.

Duas professoras relataram que, ao escolherem a lotação na referida escola, não conheciam a região e não foram informadas da situação de violência. Uma delas considerou o local por ser servido por transporte público. A outra, havia obtido liberação para se transferir de uma escola bem mais distante de sua casa para aquela que lhe pareceu, também, ter uma localização atraente. Porém, mesmo depois de ter percebido que a área era bastante perigosa, esta última decidiu continuar ali mesmo, pois gastaria menos horas de deslocamento de casa até o local de trabalho, ganhando tempo para cuidar da filha pequena, obtendo benefícios em sua vida pessoal.

Bom, com tudo isso, eu preferi ficar nesta escola. Perigo por perigo, aqui eu fico perto da minha casa, posso tomar café com a minha filha, levá-la até a condução escolar e, aqui, nossos colegas ainda avisam se a situação ficar tensa. Lá [na outra escola onde lecionava], nem isso [...].

Suas palavras chamam atenção para a importância do tempo na organização do trabalho docente. 0 tempo nas trajetórias docentes também se reveste de alta carga simbólica, demarcando a posição na hierarquia institucional a partir dos anos de experiência - concebida como acúmulo de conhecimento, ativo e qualificador dos conhecimentos e das práticas pedagógicas. A própria normatização que regula os pedidos de remoção de uma escola para outra é concedida considerando o tempo efetivo de exercício do professor no cargo e na unidade escolar ${ }^{10}$.

10- Conforme disposto da regulamentação SME n. ${ }^{\circ} 284$, de 30 de setembro de 2021, no âmbito da Prefeitura do Rio de Janeiro. Cf. https:// doweb.rio.rj.gov.br/apifront/portal/edicoes/imprimir_materia/765558/5118. Acesso em: 29 out. 2021. 
Para a outra professora, o emprego público adquirido com o ingresso na carreira do magistério municipal foi visto como uma conquista e um direito, além de uma promessa de estabilidade. Nesse caso, transparece a expectativa de poder retribuir os esforços despendidos pelos pais para que ela se formasse e iniciasse uma carreira profissional. Ambas as narrativas aparecem carregadas pela perspectiva de classe, atribuindo valor social ao exercício de uma profissão qualificada, bem como à ocupação de um cargo público. Ao mesmo tempo, a possibilidade de articular o trabalho e a criação da filha ou o cuidado para com os pais pareceu ser uma motivação preciosa. Tais aspectos também guardam relação com a identidade de gênero feminino, que se expressa no interesse em conciliar o trabalho e o cuidado da família.

Ao se referir à análise das trajetórias profissionais, Claude Dubar (2005) sublinha as relações entre dois aspectos que as conformam: os processos biográficos individuais e as dinâmicas institucionais coletivas que, por sua dimensão histórica, permitem perceber os fatores de natureza objetiva e subjetiva das identidades profissionais. Ambas valorizaram o ambiente interno da escola, destacando aspectos positivos de seu trabalho - como harmonia e interação amigável -, em contraponto às ameaças que rondavam a parte externa da escola. Supõe-se que a separação entre o que é de dentro e o que é de fora da escola tem relação com o desejo de encontrar, para si mesmas, argumentos que justifiquem a decisão de permanecer ali, como expresso a seguir:

Mas o ambiente dentro é bom, a diretora faz o máximo que pode. Tem problema como qualquer outra escola, mas o maior que é de todo mundo, fica fora dali. É o entorno, eu nunca presenciei tanto tiroteio. Antes ocorria sempre de manhã, mas agora não tem hora. No ano passado, muitas vezes eu nem ia trabalhar, pois cansavam de ligar para mim da escola dizendo para não ir. Houve um dia em que a diretora quase fechou a escola, pois foram 20 minutos de tiroteio (ou algo assim) de tiro, bomba, e as crianças chorando [...].

Não existia, à época, uma orientação padrão da Secretaria para essas situações, a não ser a recomendação de que cada escola elaborasse o seu próprio plano de segurança, tendo em vista as especificidades de cada caso ${ }^{11}$. Para além dos planos, o uso do aplicativo WhatsApp permitiu a disseminação rápida e extensiva, a todo o grupo, de informações sobre a situação em cada dia e em cada hora. No caso desse grupo de professores, acontecia tal como é explicado a seguir:

As meninas que moram na comunidade, se tem um dia que elas já acordam e sabem que tem polícia lá dentro, elas já avisam para gente entrar com cuidado. Então, o zap funciona bem nesse sentido, até para as diretoras mesmo, pois as duas moram longe [...].

11- Atualmente, circulam materiais de apoio propostos por organizações não governamentais, como o Redes Maré, que publica um boletim que divulga e analisa dados sobre a questão da violência e segurança no conjunto de favelas da Maré (Cf. https://redesdamare.org.br/media/ downloads/arquivos/BoletimSegPublica2018.final.pdf), assim como por entidades como a Cruz Vermelha com o Programa Acesso Mais Seguro, que propõe procedimentos para quem vive ou atua contextos violentos (Cf. https://www.icrc.org/pt/document/o-programa-acesso-mais-seguro). 
Elas acrescentaram que, quando o tiroteio começava na hora da entrada, as diretoras tinham autonomia para fechar a escola. Porém, quando as atividades já haviam sido iniciadas, não havia o que fazer, pois se tornava perigoso circular no entorno, restando proteger as crianças das balas perdidas que podiam adentrar a escola e tirar a vida de alguém. Com relação a esses momentos, os relatos misturam medo e pânico, cuidado e afeto. Uma das professoras falou sobre um dia especialmente difícil, em que ela foi forçada, por duas vezes, a sair da sala de aula para buscar abrigo no banheiro ou no corredor, posicionando-se fora da linha de tiro. Emocionada, ela demonstrou a reciprocidade que se estabeleceu entre ela e os seus alunos, naquele momento:

Então, nessas situações eu falo para os alunos "Gente, abaixa e se deita...” Aí alguns falam para mim: "Tia, deita você também". Aí eu me levanto e vejo quem está com a cabeça levantada e mando abaixar. Aí, alguns falam: "Tia, abaixa a cabeça!"

É curioso você ver as reações das crianças: enquanto umas choram, outras urinam e outras dormem. Outras, percebendo o meu desespero, tentam me acalmar, falando assim: "Tia, daqui a pouco vai passar, a polícia vai embora e a gente vai voltar para a sala para continuar o nosso trabalhinho". Isso cortou o meu coração [...]. 0 tiro era tão alto e perto que eu comecei a cantar com eles, tentando cantar mais alto que os tiros, pois [...] se um deles começa a chorar [...] ia ficar difícil controlar a situação [...].

Chama a atenção o sentimento de desamparo que a professora expressa de forma clara, mas também se destaca o carinho e a afeição que ela recebeu dos alunos em resposta às suas preocupações e cuidados. Fora isso, a violência das partes em confronto é forte e, algumas vezes, aparece replicada pelos pais dos alunos. Em seguida, uma visão dessa cadeia de violências:

Uma coisa que me angustia é que a gente se torna um escudo para eles. Pois eles roubam carga e, tendo a comunidade toda para estacionar o caminhão roubado, eles colocam logo na frente da creche!

Às vezes, algumas mães gritam pra gente: "Ah, são um bando de trouxas! 0 Caveirão ${ }^{12}$ não faz nada não. Não quer ver Caveirão? Então não vem trabalhar na favela”.

Nem sempre os pais se apressam para pegar os filhos [...] e a gente fica presa ali [...] acho que nós somos vistas como peça de reposição [...] a gente toma um tiro aqui, e daqui a pouco tem outra professora no lugar [...]. Mas na minha casa eu não sou essa peça substituível assim, não, eu tenho uma filha e um marido me esperando.

Parece que eu é que sou a errada, por estar aqui [...]. Porque sou eu quem preciso me esconder com as crianças [...]. Eu planejo as aulas e fico semanas inteiras sem fazer nada com elas, nem a

12- Caveirão é como os moradores chamam o veículo blindado usado pelo Batalhão Especial da Polícia do Rio de Janeiro (BOPE) para trafegar nos territórios conflagrados. 
rotina da roda de conversa a gente consegue fazer sem interrupções [...] ainda precisamos falar baixinho para podermos ouvir qualquer movimento estranho.

Os trechos expõem múltiplas manifestações de violência vindas daqueles que roubam a carga e estacionam os caminhões apreendidos na frente da escola, fazendo todos de escudo; ou da polícia, que promove operações no local sem cuidado com os escolares; além da violência dos pais, que, por já terem naturalizado a situação, não compreendem as percepções dos professores a respeito das situações que envolvem risco de morte. As professoras falam também, indiretamente, do poder público, quando expressam a sensação de serem tratadas como peça de reposição.

É claro o incômodo que elas experienciam por não conseguir realizar o trabalho sem interrupções, acrescido da solidão de estar em um local no qual a comunicação com os pais é tão difícil. 0 nível de precarização do próprio prédio escolar, extremamente exposto e sem condições adequadas para se trabalhar os hábitos de higiene com as crianças, também foi mencionado. Assim, os depoimentos oscilaram entre a desilusão e o compromisso, entre a desesperança e a perseverança lúcida, por estarem cientes dos limites de sua ação. 0 trecho abaixo é esclarecedor a esse respeito.

Eu tinha aquela fantasia de que o professor pode mudar tudo, que o professor muda a realidade do aluno. Por mais que seja bonita e poética, essa ideia é muito fantasiosa. Mas, se daqui a alguns anos eu passar e ver que um aluno meu está no tráfico, não é porque eu fui uma má professora, entendeu? 0 meu tempo com eles é muito curto, eu tenho a responsabilidade de mostrar um outro lado, uma outra realidade. Tenho, mas eu não, não posso me culpar por causa das coisas que acontecem com eles fora da escola, e eu me culpava muito... e no primeiro ano eu falava para mim mesma: "Não, é ruim, eu tenho medo, mas eu não posso sair daqui, porque é aqui que eles precisam de bons professores”. Entendeu? Mas eu perdi bastante dessa ilusão que eu tinha nos primeiros anos.

\section{A escola como patrimônio da comunidade}

Nos últimos anos, a crise pela qual passa o Estado Democrático incluiu retrocessos políticos e de direitos alcançados nas últimas décadas, tornando ainda mais complexa a questão da segurança pública. De um lado, o Estado dá demonstrações de fragilidade em vários setores de sua competência, de outro, o crime organizado tem ampliado os seus limites, expandindo o seu domínio para espaços antes impensados. Mais recentemente, o ex-governador Wilson Witzel (2019-2021) vinha promovendo a militarização das escolas públicas, acreditando ser uma grande medida. No entanto, não foram anunciadas políticas de segurança mais amplas, articuladas a projetos sociais, apoiadas em inteligência técnica e tampouco numa abordagem intersetorial, integrando vários órgãos públicos para fazer frente ao problema. Apesar de tudo, enquanto as políticas estatais não produziam resultados, os professores seguiam mobilizando o que Michel de Certeau (2000) chamou de politização das práticas cotidianas. Essa noção permite perceber movimentos de construção de redes e padrões de conduta coletiva que garantem uma apropriação das normas oficiais, gerando normas adaptadas às necessidades e às situações que se apresentam. 
A politização das práticas ordinárias continua sendo uma chave importante para enfrentar o problema e que aparece nas narrativas de uma ex-diretora. Para ela, a comunicação fundada no diálogo é um procedimento crucial. Ela destacou ainda a importância do diálogo acerca das interferências do tráfico, pontuando algumas "regras de ouro" para um diálogo controlado e seguro: em primeiro lugar, fale com quem te procura para conversar; em segundo lugar, jamais aceite qualquer oferta de ajuda do tráfico, como pintar a escola ou coisas do gênero; em terceiro lugar, e mais enfatizado, a diretora deve demonstrar autoridade, ainda que a abertura da escola, sendo proibida pela Secretaria, esteja sendo exigida, pela força (com apoio do tráfico). Então, ela e as diretoras que a sucederam demonstraram autoridade, fazendo as exigências possíveis em meio à relação de forças desiguais. Tais exigências eram a favor da preservação do patrimônio (material e cultural) da escola, como ela explica, a seguir:

Penso eu que escola não pode se aliar a esses sujeitos, não se pode pedir coisas, fazer concessões, nós nunca pedimos proteção ao tráfico. Eu nunca pedi e acho que quem esteve lá, depois de mim, também não. 0 que a gente sempre fez foi tentar mostrar a situação, então por exemplo: os bailes começaram a acontecer [...] e foram um inferno na nossa vida, um inferno, a gente não podia proibir o baile, mas a gente deixava algumas regras estabelecidas no espaço da escola. Elas eram descumpridas muitas vezes, mas a gente sempre reafirmava as mesmas regras [...]. Se alguém fala [...]. "Ah vamos fazer baile sim, nem que seja na marra [...]" e a gente responde que não pode, mas diante da pressão e do desequilíbrio de forças, eu posso tentar buscar caminhos, que caminhos são esses? "Tem aula na Educação [de] Jovens e Adultos à noite e essa aula precisa ser respeitada.” Então [...] você dialoga, não sendo conivente e, ao mesmo tempo, tenta mostrar que aqui quem manda é você... Você também não pode colocar a sua vida a prêmio, eu nunca fiquei no portão agarrada dizendo que não podia ter baile, mas eles sempre souberam que nós éramos contrárias à realização do baile e que algumas regras não poderiam ser ultrapassadas (como deixar cacos de vidro no pátio ou depredar o prédio e os equipamentos escolares). Eu acredito, por exemplo, que a questão do roubo na escola nunca tenha acontecido até hoje, porque eles acabaram entendendo que a escola é um patrimônio da comunidade [...].

0 diálogo também foi valorizado no relacionamento com os alunos. 0 grupo fez referência à linha tênue que permeia a decisão de alguns alunos de seguir com os estudos ou de entrar para o tráfico. Nesse caso, a avaliação foi de que valia falar abertamente sobre isso com os alunos e cobrar deles uma atitude. Ao lado dessas conversas, eram realizados, no âmbito das atividades escolares, eventos e aulas disseminando informações sobre os efeitos do uso de drogas ilícitas na saúde dos consumidores. Ainda que conhecessem os limites dessas ações, elas não deixavam de intervir, na esperança de obter algum resultado, por menor que fosse.

Vale lembrar que a parcela de alunos que entram para o tráfico é reduzida em relação ao número total. Mas também é certo que isso despertava tristeza entre as professoras, que viam essa situação como uma derrota. Era comum elas apontarem para jovens que circulavam nas redondezas e falarem: "Você está vendo aquele ali? Ótimo aluno, que tristeza, perdemos ele para o tráfico!” Como sugere esse comentário, atuar nessas escolas é, de fato, como atuar em um campo de guerra, em que cada batalha enfrentada é 
comemorada e cada derrota é sinceramente lamentada. Em seguida, se apresentam outras formas de violência que permeavam o cotidiano escolar:

0 primeiro ano foi uma loucura, as crianças se batiam o tempo inteiro, as vezes até tiravam sangue. 0 desafio foi tentar mostrar (e trabalhar) através do teu exemplo que é possivel a gente se relacionar com o outro de um modo diferente da forma de bater, de xingar, de agredir [...] esses jovens vêm de uma situação de opressão, de violência física e verbal o tempo inteiro e eles trazem para a escola essa violência já entranhada no seu comportamento. Eu não posso é reagir desta mesma maneira, senão eu não viro esse jogo. Então, eu acho que cotidianamente lidar com essas crianças, com esses jovens e adultos que sofrem todo tipo de violência sem adotar uma prática de violência é um desafio que a gente perseguiu o tempo inteiro, o tempo inteiro [...].

A força do exemplo apareceu como outro procedimento-chave para educar as crianças, os jovens e os adultos que frequentavam a escola. Assim, elas relativizaram a violência armada, embora esta fosse a mais radical por ameaçar a vida, mas realçaram a existência de outras formas de violência, menos visíveis. Alba Zaluar (1999) adverte que, na escola, a violência apresenta uma dupla dimensão: a violência física perpetrada por traficantes ou bandidos, assim como por alguns dos agentes do poder público encarregados da manutenção da ordem e da segurança; e a violência que se exerce pelo poder das palavras que negam e oprimem psicologicamente o outro. A autora acrescenta, ainda, a violência exercida pelos alunos, entre eles e contra os professores.

Para essa última forma de violência, Debarbieux (1998) cunhou a noção de incivilidade, caracterizada por práticas cotidianas que expressam uma lógica antagônica à socialização escolar pela falta de polidez e por atos que geram irrupções de desordem constantes no ambiente escolar ${ }^{13}$. As professoras lidaram com essas incivilidades, ou seja, com a violência de dentro, bem como a violência de fora, percebendo as articulações existentes entre uma e outra, mas não recuaram diante dos princípios que elas consideravam legítimos. Evocando o diálogo, o esclarecimento e a informação, legitimando suas falas por meio de exemplo de conduta e seguindo à risca o princípio da igualdade de tratamento, elas foram moldando suas práticas profissionais na interação com o grupo de profissionais da escola e dos níveis gestores, assim como no diálogo com os alunos e suas famílias. Vale reproduzir um trecho da narrativa que se segue para explicitar como vai se operando a politização das práticas docentes diante de situações potencialmente violentas.

Alguém diz: "olha, ih! Esse garoto é filho do bandido e tal [...]." E eu respondo: "Ele é filho, mas aqui ele é aluno, aqui ele vai estudar”. Então é ver (no sentido de enxergar) quem está ali: "E oh! esse garoto que entrou [...] é do tráfico". Não interessa! Se ele se matriculou, ele vai ser tratado como aluno, respeitado como aluno [...]. Eu considero importante tentar mostrar que nós não somos amiguinhos, mas nós temos um papel a cumprir ali dentro que é o papel de garantir

13- Na enquete da Organização para a Cooperação e Desenvolvimento Econômico (OCDE), 12,5 por cento dos professores ouvidos no Brasil disseram ser vítimas de agressões verbais ou de intimidação de alunos pelo menos uma vez por semana. Trata-se do índice mais alto entre os 34 países pesquisados, que apresentam uma média de 3,4 por cento. Disponível em: https://www.bbc.com/portuguese/noticias/2014/08/140822 salasocial_eleicoes_ocde_valorizacao_professores_brasil_daniela_rw. Acesso em: 30 maio 2017. 
educação às pessoas que procuram aquele espaço. Não tem fórmula de enfrentar, não tem. Só tem princípios. Ter o grupo junto, não estar sozinha, ter princípios em que você acredita, dos quais você não pode abrir mão [...]. Procurar não gerar situações de cumplicidade que te deixem refém de alguém [...] e, em alguns momentos, sentar e chorar [...] e no outro dia ver o que se vai fazer.

A compreensão sobre as condições de vida dos alunos, bem como dos micropoderes em interação no ambiente escolar e em seu entorno, permitiu que as professoras em cargo de direção planejassem ações que transformaram os modos de se relacionar no contexto escolar. Agindo desse modo, elas garantiram coesão e consenso entre os profissionais da escola. Essa construção coletiva foi obtida em ocasiões de trabalho conjunto e em espaços de interação do corpo docente para discussão sobre o próprio ofício. Elas tiveram que ampliar esses espaços, na medida das necessidades da escola, respeitando as possibilidades ao alcance da direção. Elas também deram continuidade nesse trabalho, tendo mais de um mandato na direção da escola e orientando sucessoras comprometidas com o projeto forjado coletivamente.

\section{A escola republicana ainda se impõe!}

Conforme foi demonstrado, a fabricação de consensos mínimos é extremamente importante para o funcionamento da escola e o desempenho dos professores. Sem o apoio mútuo da direção e dos professores da escola fica muito difícil enfrentar os problemas que se apresentam. Ademais, sem um projeto mais amplo, que extrapole a mera transmissão dos conteúdos disciplinares, os professores desistem da profissão. A desistência pode se dar por meio da indiferença e da negação de sentido em seu cotidiano, por meio do absentismo ou do presenteísmo. Conforme observaram Paschoalino e Altoé (2015), o presenteísmo denota a presença física apartada de qualquer envolvimento emocional, sobretudo diante de desafios extremos. Esses padrões de comportamento apareceram em outras narrativas, mas, por motivos óbvios, não serão objeto de debate neste momento.

Focando o conjunto de depoimentos apresentados, é possível afirmar que tanto o primeiro quanto o segundo grupo de professoras que colaboraram com a pesquisa expressaram a clara noção de que a profissão docente tem como metas de longo prazo temperar o desejo (irracional) dos alunos com a compreensão de que, para se ter o que se deseja, de forma duradoura, é necessário adotar condutas baseadas na racionalidade e, logo, no autocontrole das pulsões (ELIAS, 1993). Desse modo, elas visaram ampliar a autonomia dos alunos, sobretudo no que tange à capacidade de expressão e à habilidade de participação política, pois, nas democracias, o reconhecimento de direitos requer que se lute por eles. Por isso, as professoras se preocuparam em fixar normas e limites, disseminar informações e desenvolver o pensamento racional, aliado ao reconhecimento e tratamento dos alunos como sujeitos de direitos.

Nessa linha, a leitura de Ribeiro (2000) sugere que a ideia do dever (profissional) - aquela que pode levar a uma ética do sacrifício - é o que toca um dos mais elevados princípios republicanos, qual seja, a preocupação com o bem comum. Como assevera o autor, a renúncia às vantagens privadas em prol do bem comum - que pode ser nomeada como virtude ou abnegação - não é um sentimento natural e, por isso, necessita ser 
construído por intensa educação. Nesse aspecto, as professoras assumem o desafio de reproduzir essa ética em prol da construção democrática, em um meio no qual a carência obscurece a capacidade racional e a opressão dificulta a habilidade de transformar o desejo errático em interesse racionalmente calculado.

As professoras mais jovens enfatizaram situações de desamparo e, simultaneamente, de apoio recíproco experimentadas junto aos seus alunos e na convivência privada com os seus familiares. Já as professoras mais experientes operaram argumentos de modo a relativizar os efeitos dos conflitos armados no entorno de suas escolas, identificando outras formas de violência que circulavam no ambiente escolar. Parece que a decisão de não dramatizar a questão, ou até mesmo de não se portarem como meras vítimas, pesou na linha narrativa que elas seguiram, em uma espécie de consenso não planejado. Demonstraram, assim, que, para além do mal-estar que as situações de violência provocam, é necessário buscar bem-estar na realização do próprio trabalho.

0 bem-estar docente foi objeto de estudo de Rebolo e Bueno (2014). Em artigo sobre o tema, as autoras ressaltaram a importância de se compreender, para além dos fatores do mal-estar docente, as condições que revertem em bem-estar. Assim, ainda que as professoras enfrentassem uma série de problemas em sua rotina, havia situações que lhes proporcionavam algum bem-estar. Atentar para essa questão não é irrelevante, como sugerem as autoras, tendo em vista que a satisfação no trabalho tem um peso significativo para que os professores permaneçam na profissão e nas instituições em que atuam. Com base na literatura sobre o assunto, Rebolo e Bueno (2014) elencaram alguns fatores de ordem objetiva e subjetiva que contribuem para proporcionar bem-estar aos professores.

No caso estudado, os fatores de ordem objetiva, tais como a infraestrutura das escolas, nem sempre contribuíram para proporcionar bem-estar, como observado. Em relação à condição de trabalhar em áreas de risco, esse fator objetivo induziu movimentos subjetivos, tais como a formação de redes de informação e interação, com a utilização de aplicativos como o WhatsApp. Também gerou, como vimos, uma forma de interação com os alunos baseada no cuidado e proteção nos momentos de maior risco, criando relações fundamentadas na solidariedade e na mútua proteção. Na escola da Quarta CRE, configuraram-se situações de caráter relacional que propiciaram maior coesão e participação do corpo docente na definição de um projeto pedagógico de longo prazo, assim como na urgência da tomada de decisões difíceis, por exemplo, a de fechar a escola.

Os pequenos retornos que as professoras receberam dos alunos e de suas famílias contribuíram grandemente para a percepção, ainda que subjetiva e pessoal, de que o seu trabalho estava dando frutos. Do ponto de vista socioeconômico, é certo que as condições salariais não são animadoras, mas a estabilidade no emprego ainda foi valorizada por algumas professoras. Elas também enfatizaram o valor social e político da docência, percebendo a escola pública como um dos poucos espaços abertos à população desses territórios que se ocupam da formação de sujeitos de direitos. Considera-se que esse é o valor que realmente influenciou a decisão das professoras participantes desse recorte da pesquisa sobre permanecer nessas escolas.

Como elas disseram, não há fórmulas e, acrescenta-se, também, não há políticas delineadas para o enfrentamento racional e planejado da questão. Porém, isso não paralisou as professoras e nem as demoveu de seu papel no exercício do magistério. Interessante 
observar o tratamento igualitário concedido a todos os alunos, independentemente de suas (possiveis) ligações com o tráfico, sendo a igualdade de tratamento entendida como um princípio democrático caro ao ideal republicano. Por outro lado, a insistência na defesa do patrimônio escolar pode ser vista como uma tática de estabelecer regras possíveis, visando a preservação do bem comum num contexto marcado por relações assimétricas de poder.

A certeza de que a educação escolar deve se fundar em princípios que prezam o reconhecimento da liberdade e da igualdade, bem como numa ética que valorize o bem comum e que se firma em regras ou leis que devem ser respeitadas por todos, parece ser consensual. Isso é o que vem alimentando o trabalho e dando força ao enfrentamento de múltiplos conflitos. Além de tudo, a crença no poder libertador da escola premia e afaga o coração dessas professoras, como ficou claro quando uma delas narrou, com alegria, o carinho e a preocupação que os alunos expressaram com a segurança dela nas horas mais difíceis. Aparece, também, quando uma ex-diretora contabilizou zero furtos na escola, apesar de essa não ser uma realidade comum em outras escolas com as mesmas características.

Acredita-se que o sentimento de bem-estar tem relação com os resultados positivos do trabalho e confirmam a consciência da autoridade e da responsabilidade com que as professoras se viam investidas enquanto agentes públicas (o que não se reduz a ser representante do Estado), assim como na adoção de modos de convivência e tratamento atento e respeitoso com os alunos, ampliando as possibilidades socializadoras da convivência escolar.

Conforme observou Van Zanten (2008), em estudo sobre a influência do local de exercício na socialização profissional de professores secundários na França, os docentes que atuavam em escolas difíceis lidavam com suas realidades segundo (pelo menos) duas lógicas distintas. Alguns estabeleciam estratégias de sobrevivência naquela realidade até quando estas se esgotavam e eles se viam tomados por um comportamento ritualístico, desengajado ou desiludido com seu trabalho. Esse grupo percebia a sua entrada nessas escolas como uma etapa curta e difícil de sua carreira e desejavam sair dali o quanto antes. 0 outro grupo, ao contrário, desenvolveu uma visão positiva dos alunos e da comunidade na qual essas escolas se localizavam, passando a perceber o local como espaço de experimentações e aprendizagens profissionais. Desse modo, foram desenvolvendo o que a autora chamou de domínio do ofício (ZANTEN, 2008) e, pouco a pouco, foram adquirindo uma boa reputação. Talvez as observações da autora ajudem a compreender melhor o que mantém essas professoras nas escolas em que atuam, apesar das violências que marcam o seu cotidiano. Para finalizar, apresentam-se algumas hipóteses que podem, de algum modo, contribuir para ampliar essa discussão, com desdobramentos em debates futuros.

\section{Considerações finais}

Cruzando as referências anteriormente destacadas com os depoimentos das professoras, percebe-se que a crença no valor de seu trabalho certamente contribuiu para um certo bem-estar profissional e para a sua permanência nas escolas. Isso porque o compromisso ético e político com os alunos que vivem em situação de vulnerabilidade constitui uma justificativa nobre, que fortalece os docentes no enfrentamento das tensões 
e das guerras que perturbam o seu trabalho. Isso não significa que o problema está resolvido. Longe disso! Os dados sobre o percentual de licenças médicas entre docentes para tratamento psiquiátrico aumentaram consideravelmente no Brasil e no Rio de Janeiro ${ }^{14}$ Por outro lado, os índices de abandono da profissão e um desalento generalizado vem dando o tom da situação do professorado atualmente, ainda que as informações a esse respeito, sobretudo no Rio de Janeiro, não tenham a transparência requerida. Contudo, a percepção de que a docência pode contribuir para o bem comum continuou dando suporte e valor ao trabalho dessas profissionais.

Por fım, é necessário evitar repetir a tecla da formação insuficiente, da resistência às mudanças e da passividade dos professores. 0 que se pode observar é que o trabalho docente, quando informado de suas potencialidades políticas e transformadoras, ganha uma dimensão dinâmica e ativa, se configurando como espaço de lutas, de militância e de realização pessoal e profissional.

Foi com esse objetivo que se escolheu como eixo orientador destas reflexões o questionamento sobre as motivações das professoras para permanecer em seus postos de trabalho a despeito das adversidades. Como resposta, encontrou-se a crença no potencial republicano e democrático da escola pública, junto ao empenho em fazer valer as contribuições políticas e sociais de seu trabalho, tanto no domínio público quanto na vida privada. Se não há fórmulas, fica a certeza de que o pensamento e a ação esclarecidos e críticos, associados ao trabalho coletivo e a formação de redes de apoio mútuo, são a base de uma atuação profissional criativa, autônoma e relevante.

\section{Referências}

BURGOS, Marcelo Baumann. Cidade, território e cidadania. Dados, Rio de Janeiro, v. 48, n. 1, p. 189-222, 2005.

CAMPAGNUCCI, Fernanda. Silêncio dos professores? Uma interpretação sociológica sobre a "ausência" da voz docente no jornalismo educacional. 2014. Dissertação (Mestrado em Educação) - Faculdade de Educação, Universidade de São Paulo, São Paulo, 2014.

CERTEAU, Michel de. A invenção do cotidiano: artes de fazer. Petrópolis: Vozes, 2000.

DEBARBIEUX, Eric. Violence à l'école, incivilité et postmodernité. Revue Française de Pédagogie, Lyon, v. 123, n. 1, p. 7-19, 1998.

DUBAR, Claude. A socialização: construção das identidades sociais e profissionais. São Paulo: Martins Fontes, 2005.

\footnotetext{
14- Dados divulgados na imprensa afirmam que, em 2018, a Secretaria de Educação do Rio de Janeiro concedeu 3.055 licenças por doenças relacionadas ao estresse ou depressão. 0 número corresponde a 8 por cento do quadro de professores do município. Disponível em: https:// www.dw.com/pt-br/a-viol\%C3\%AAncia-contra-professores-no-brasil/a-48442455. Acesso em: 29 jan. 2020. Por seu turno, sinopse realizada no âmbito da pesquisa Trabalho docente na educação básica no Brasl, de 2010, informa que a segunda maior incidência de licença médica no Brasil está ligada à depressão, ansiedade, síndrome do pânico (14,3 por cento) e estresse (11,7 por cento). Disponível em: http://gestrado.net.br/images/ pesquisas/5/Sinopse_SurveyNaciona n I_Educacaolnfantil_TDEBB_Gestrado.pdf. Acesso em: 12 jan. 2020.
} 
DUBET, François. Le declin de l'instituition. Paris: Du Seuil, 2002.

ELIAS, Norbert. 0 processo civilizador. Rio de Janeiro: Zahar, 1993.

HAESBAERT, Rogério. 0 mito da desterritorialização: do "fim dos territórios" à multiterritorialidade. Rio de Janeiro: Bertrand Brasil, 2004.

LORIGA, Sabina. A tarefa do Historiador. In: GOMES, Angela Maria de Castro; SCHMIDT, Benito Bisso (org.). Memórias e narrativas autobiográficas. Porto Alegre: UFRGS; Rio de Janeiro: FGV, 2009. p. 13-38.

PASCHOALINO, Jussara Bueno de Queiroz; ALTOÉ, Adailton. Presenteísmo e trabalho docente. Curitiba: CRV, 2015.

REBOLO, Flavinês; BUENO, Belmira Oliveira. 0 bem-estar docente: limites e possibilidades para a felicidade do professor no trabalho. Actas Scientiarum, Maringá, v. 36, n. 2, p. 323-331, 2014. Disponível em: https://www.redalyc.org/pdf/3033/303331286016.pdf. Acesso em: 20 jun. 2019.

RIBEIRO, Renato Janine. Democracia versus República. In: BIGNOTTO, Newton (org.). Pensar a República. Belo Horizonte: UFMG, 2000. p. 3-24.

SENNETT, Richard. 0 declínio do homem público: as tiranias da intimidade. São Paulo: Companhia das Letras, 1999.

ZALUAR, Alba. Um debate disperso: violência e crime no Brasil da redemocratização. São Paulo em Perspectiva, São Paulo, v. 13, n. 3, p. 3-17, 1999.

ZANTEN, Agnès Van. A influência das normas de estabelecimentos na socialização profissional de professores: 0 caso de professores de colégios periféricos franceses. In: TARDIF, Maurice; LESSARD, Claude (org.). 0 ofício de professor: história, perspectivas e desafios profissionais. Petrópolis: Vozes, 2008. p. 200-217.

Recebido em: 08.04.2020

Aprovado em: 02.06.2020

Libania Xavier é professora titular do Programa de Pós-graduação em Educação da Universidade Federal do Rio de Janeiro. Autora dos livros Associativismo docente e construção democrática (Brasil-Portugal: 1960-1990), de 2013, pela editora da Universidade do Estado do Rio de Janeiro (UERJ), e 0 Brasil como laboratório: educação e ciências sociais no projeto dos centros brasileiros de pesquisas educacionais CBPE/Inep/MEC (1950-60), de 1999, pela editora da Universidade São Francisco (USF). 